\title{
Multilingual Education in China: Taking the Situation of Guizhou Minority Areas as an Example
}

\author{
Feifei Shan \\ School of Foreign Language, Southwest University, Chongqing, China
}

\begin{abstract}
Multilingual education has long been implemented and addressed in recent years in China, as a nation multi-ethnicities. The prominent ethnic, linguistic and cultural diversity make the situation of multilingual education in China complex. Therefore, it is necessary to provide an overview of the situation of multilingual education in China to first present the full status-quo situation to educators and researchers, to provide basis for relevant teaching practice and research and to pave the way for further in-depth research. The paper first provides an overview of the situation of Chinese multilingualism, and presents ethnic multilingual policies and practices in China in general, then particularly focuses on the practice of multilingual education in Guizhou minority areas.
\end{abstract}

Index Terms - multilingual education, multilingual policies, multilingual practices, China, Guzhou minority areas

\section{INTRODUCTION}

China is a multinational country with the total number of 56 nationalities, among which Han majority comprised of nearly $91.5 \%$ of the total population, and the rest are 55 officially-organized minority groups, constituting approximately $8.5 \%$, with a combined population around 114 million (2010 National Census). Residing in over $60 \%$ of the land, ethnic minority groups are hugely diverse in terms of history, culture and language.

To address the prominent ethnic, linguistic and cultural diversity, the central government of PRC has made a series of top-down policies and laws to legitimize and foster the multilingual education drawing on a political framework of Duoyuan Yiti (ethnic diversity within national unity) (Fei, 1989). The core under the perception of China as a state of Duoyuan Yiti is the stakeholders' belief that national unity and ethnic diversity are the foundation for facilitating to promote socioeconomic development regarding 56 ethnic groups and establish harmonious ethnic and social relationships.

The interrelationship between the centrality and diversity presents the complexity and dynamics of the overall context. The centrality of government as a unified ethnically nation makes ethnic minority groups ruled under the same laws and legislature as the Han majority and are constitutionally granted equal rights. One the one hand, Putonghua, the standard Chinese, are promoted throughout the country including minority-dominant communities, on the other hand, minority ethnic groups are granted by national constitution to use and maintain their languages, which paves the way for later bilingual and trilingual education in ethnic minority areas. The central and local governments have formulated and implemented Chinese - native language bilingual education policies in minority areas since the formation of the People's Republic of China. Since the turn of the century, language policies in education were designed for ethnic minority groups to foster trilingualism attributable to the spread of English. Sanyu Jiantong (mastery of three languages, i.e. the minority native language L1, Chinese as L2 and English as L3) has thus become the goal of language education in minority areas and Sanyu Jiaoyu (trilingual education) has expanded quickly (Feng \& Adamson, 2015), which is beneficial to the development of ethnic minority education and language and an efficient approach to improve ethnic education and maintain and transmit ethnic minority culture.

\section{Minority Languages In China}

China is also a linguistically diverse nation for its multi-ethnicities. The ethnic minority groups, except for Hui and Man who speak Chinese now, all have their own home languages, with some having more than one. Thus, it is estimated that a total of more than 80 languages from 5 language families, i.e. Sino-Tibetan, Altaic, Austronesian, South Asian and Indo-European were spoken by indigenous minority groups. Sino-Tibetan includes Chinese, Tibeto-Burman, Miao-Yao, Zhuang-Dong; Altaic includes Turkic, Mongolian and Manchu-Tungusic languages; Austronesian includes dozens of languages of Gaoshan minority nationalities; South Asian includes Mon-khmer, Indo-European are mainly Russian and Tajik; and the family of Korean and Jin. The ethnic minorities mostly with big population, with a total number of 24, have their own traditional written scripts, sometimes more than one, amounting to a total of more than 33 . (Gu \& Luo 2003) 
Zhou (2000) categorized minority languages into three types according to the history of their writing system and their use in education in minority regions. Type 1 communities have had their own functional writing system widely used before the founding of the PRC in 1949 and have continued to use the spoken and writing system in education up to now, including five ethnic minority groups of large population, i.e. Korean, Kazak, Mongolian, Tibetan and Uygur. Four of them, with the exception of Korean located in an autonomous prefecture in Jilin in the north-east, all inhibit in communities along China's borders. Type 2 communities had their own functional script in place before 1949 and only occasionally have bilingual education since 1949, including Dai, Jingpo, Lisu, Lahu, Miao, Naxi, Va and Yi minority groups residing mainly in the south-west of the country. The remaining 42 ethnic groups are Type 3 communities, which only had no fully functional or no pre-existing scripts before 1949 and scarcely or limitedly use their language in education.

Because China's ethnic minority groups mainly live together over large areas while some live in individual concentrated communities in small areas, the language use in China shows a variety of types, mainly including minority monolingual areas, minority language(s)-Chinese bilingual or multilingual areas and Chinese monolingual areas. According to the frequency of language use, bilingual or multilingual areas can be divided two kinds: the areas mainly using of Chinese and the areas mainly using of minority language(s).

\section{Multilingual Practices of Minority People}

Under the political framework of Duoyuan Yiti, Chinese government has promulgated both the unified legislature and laws for both Han majority group and minority groups, and some laws and policies that specifically apply to minority groups to constitutionally mandate their equal rights (e.g. The Constitution..., 1982; The Law of ..., 1984; The Law of, 2000). A common point in all these documents legitimizes Putonghua, the standard Chinese language, throughout the country including minority-dominated communities, although they are also guaranteed constitutional rights to use and maintain their language.

Generally, the linguistic practices in minority communities can be divided into the following categories: (1) most members can speak minority home language, and only a small number of people can speak Chinese. They mainly live in the autonomous regions where there are a large number of concentrated population, such as Zang in Tibet, Mongolia in Inner Mongolian herding areas, Hmong in Leishan and Dong in Rongjiang of Guizhou, etc. In these areas, except for some cadres and educated young people, minority members cannot understand and speak Chinese as a result of their remote location, inconvenient transportation as well as underdeveloped economy. (2) Minority members mainly use their mother language to communicate, but most of them also speak Chinese. They mainly live in the relatively central towns or cities with Han people, and thus have been influenced by Han culture, such as Zhuang in Guangxi, Bouyei in Anlong. These communities usually have large population and concentrated residences. (3) Most minority members shift the communicative tool to Chinese, only a few old people can speak minority language. They mainly live dispersedly near towns and cities with convenient transportation, such as Man in Liaoning, and Qilao in Qinglong of Guizhou. (4) Some minority groups are multilinguals, who can speak their native language, Chinese and one or two other minority languages. They are usually minority groups with a small number of population and live in villages with the other large minority groups. This case can be found in Guizhou, such as Yao people in Liping, who can speak Chinese, Dong and Hmong. In addition, any relatively large ethnic minority group may speak several mutually unintelligible 'dialects', such as Tibetans. (Denwood, 1999; Feng and Adamson, 2015). Therefore, multilingual education is a special educational form that Chinese government implements in minority areas to address the multilingual need of minority groups. Since the 1950s, bilingual education was carried out to promote Chinese and ethnic minority languages. At the turn of the century, After English was introduced widely into the school curriculum, trilingual education or multilingual education was implemented and developed rapidly, accounting for a very important part in minority education of China.

\section{Modes of Multilingual Education in China}

In the PRC, as elsewhere in the world, the concept of multilingual education can be a complex and contested construct. In the simplest definition, it refers to the use of two or more languages for teaching and learning with the educational objectives of multilingualism and multiliteracy. In a narrow definition, literacy is developed and/or specific school subjects are taught through the medium of more than one language. In the minority areas of China, multilingual education, in a broader sense, includes the teaching and learning three languages as part of the curriculum within or out of formal school education. And in a narrow sense, it refers to the use of three different languages as the media of instruction to teach different content areas: for instance, the use of minority home language or standard Chinese, or both to teach most subjects and the use of ethnic minority language or/and Chinese or/and English to teach English. The multilingual education of the PRC, as Adamson and Feng (2009) observe, is to "foster trilingualism in ethnic minority areas with three goals: to enhance literacy, to assure internal stability and to allow knowledge transfer in order to strengthen the nation" (p. 9).

The approaches to the practices of multilingual education, although legislated at the national level, are different widely due to a number of geographical, economic, political and linguistic factors. Four distinct models are recognized 
among various minority areas: the Accretive, Balanced, Transitional and Depreciative (Adamson \& Feng, 2014; Feng \& Adamson, 2015).

The Accretive model emphasizes strongly on the ethnic minority language. The ethnic minority language is most often functioned as the medium of instruction. Chinese and English are taught as school subjects. Minority language is stressed in the school environment as is shown by notices, school documents and the playground language. This model is mainly found in the language communities where their ethnic minority languages have strong vitality, such as IMAR, Yanbian Korean Autonomous Prefecture. It trends to accrete the competence of three languages. The proficiency of students' L1 is ensured and thus their ethnic identity is maintained, at the same time the competencies of L2 and L3 are complementary in these regions where resources and regional policies are favorable.

The Balanced model pays almost the same attention to ethnic minority language and Chinese. Minority language and Chinese are both addressed by using them as medium of instruction and supporting bilingual environment as manifested by Chinese and minority language notices on the wall, spoken interactions between the teachers and students. English is taught as subject in the curriculum and Chinese and minority languages are used to help students understand difficult points, according to students' language preference and teachers' nationalities. In the model, the ethnic language is encouraged and the needs of students to learn through their native language are supported. The model is often found in the mixed ethnic communities, displaying more ethnic diversity. For example, the ethnicity of the teachers and students are usually found to be half Han majority and half ethnic minority, such as some schools in Mongolia. This model is also likely to develop students' strong competence in L1 and L2 thus promote ethnic harmony, and improve performance in other school subjects, as well as L3 English.

There are two cases in Transitional model. The first one existed in some mixed communities, especially in towns and cities where ethnic minority groups are dominant, but they have great socioeconomic interactions with Han majority in Chinese. The medium of instruction in school is predominantly Chinese and the dominant minority language in the area is taught as subject in the curriculum to all students, regardless of their respective ethnicity and mother tongue. Second, in many remote villages where one minority language dominant and there are little opportunities to speak Chinese for students before school, minority language is used as the medium of instruction from Grade1 to 3. Starting from Grade 3 or four, all subjects are taught in Chinese. Chinese is taught as a school subject and English is also taught as school subject most often beginning from Grade 3, with Chinese as medium of instruction. In this model, ethnic minority language is limited in the curriculum provision to the early stages of elementary school before transiting to is school dominant Chinese. This model trends to emphasize L1 and deem L2 just as a stepping stone, thus assimilate pupils into the mainstream, which is less effective to the mastery of three languages.

Depreciative model is the weak form of trilingual education. In schools that claim to be ethnic minority language school but do not use minority language as medium of instruction in reality or even not teach it as school subject. In such schools, bilingual education refers to the teaching of Chinese and English and the claiming of trilingual just take the ethnicity of students into consideration. These schools are usually found in the language communities where the vitality of ethnic minority language is relatively weak. The outcome of this model is the loss of students' L1, thus their ethnic identity.

In summary, four models can be arranged in a continuum, moving from the predominance of the ethnic minority language at one end to the predominance of Chinese at the other. English is taught in all these models although the provision and resources and thus quality are various in schools in different regions. The medium of instruction in English teaching in minority areas also aligns with the line of the continuum. Each model is formed in a complex ecology shaped by geographical, demographical, linguistic, pedagogical, historical, economic and political factors. The first two models are found in Type in most areas of 1 and Type 2 community where there are economic stability and policy supports, which are likely to produce addictive trilingualism. The last two models are commonly found in Type 2 and Type 3 where the dominant minority groups have considerable interaction with Han and the other ethnic groups and the maintenance of their languages receive little political commitment, which may result in subtractive trilingualism.

\section{The Status Quo of Multilingual Education in China}

As mentioned above, languages in multilingual education have been treated differently under the influence of political ideologies and pragmatism, as reflected in education policies. Standard Mandarin are emphasized all the time since the 1950s. The treatment of minority languages that have experienced support and suppression at the different stages of nation-building, now are strongly promoted under the political ideology of 'multi-culture' and the 'the overseas publicity of Chinese culture'. At the beginning of 2000s, English is encouraged from upper primary school. These three language policy strands have arisen differently, resulting in the imbalance in the development of trilingual education across the country. Chinese is predominant in education throughout the country including minority-dominated areas. English is gaining increasingly important status in recent times under the pressure of globalization. The status of minority languages and the state policies varies from regions due to geographical, demographical, historical, socio-cultural and political factors.

Although it would be impossible to give a full description of multilingual education in all the ethnic minority groups due to the vast differences in education across regions, it is indisputable that education of any type in most minority areas is disadvantaged because most inhabit in remote, rural, desert or mountainous areas. According to the statistics, 
one third of poverty-stricken counties are found in the west China. Schools in most of these regions, therefore, lack basic resources (Yang, 2005). Without sufficient teaching facilities and qualified teachers, minority students usually perform poorer than their Han majority counterparts (Hu, 2007; Jiang et al., 2007; Tsung, 2009). Many minority pupils cannot achieve age-appropriate proficiency either in their native language or L2 (Chinese). Their L3 (English) learning, contrary to the supportive hypothesis from some European model (Cenoz, 2003; Clyne et al., 2004), have various cognitive, cultural and psychological problems (Adamson, Feng 2014).

It is worth noting that some minority groups of Type 1 communities in China's north boast a better performance in trilingual education than those in China's west. In cases such as Koreans, students can develop trilingual competence and have strong identification with trilingual education for all three languages can be linguistic capitals in their social life, economic development and personal prospect. Therefore, they are empowered by developing trilingual competence and their economy, and confidently claiming their identity rather than being assimilated into mainstream society (Feng \& Adamson, 2015).

As previously stated, the forces of globalization accelerate the shift from traditional bilingualism to trilingualism in education of indigenous minority regions. The PRC has promulgated language policies (Ministry of Education, 2001 a, $\mathrm{b}, \mathrm{c}$ ) in education to promote English language education at all levels throughout the country. English is now commonly taught as a school subject in ethnic minority regions, and becomes a major course usually starting from Grade three. However, there is still no specific policies and curriculum standards for foreign language education of minority regions. The English language education in minority regions, therefore, can be only implemented by 'the English curriculum standards of nine-year compulsory education', which is designed for general English education in China and does not certainly suit for English education in minority regions (Zeng, 2010). In addition, teaching material, pedagogy and other educational means in present English education of minority regions do not take minority students' linguistic, cognitive and psychological factors into consideration, proved to benefit little to minority students. Therefore, it is essential to seek suitable pedagogy and build a complete system of minority trilingual education.

\section{Multilingual Education in Dong Minority Area of Guizhou}

Dong minority group belong to Type 3 community according to Zhou (2000), which only has spoken language and no pre-existing written scripts before 1949 . They are mainly distributed to the mountainous west of China, and more than half of them reside in Guizhou, one of the poorest of all the Chinese provinces. The language of education in elementary school is Chinese of both oral and script forms. In most towns and cities, ethnic minority groups have sufficient interaction with Han majority and other ethnic groups. Schools are referred as minority schools in terms of the ethnicity of students. Most students have fully developed oral proficiency in Chinese before school, all subjects are taught in Chinese, minority language is seldom used and taught in schools.

But in many villages, most students are from monolingual minority families and non-proficient in both spoken and written form of Chinese before schooling. They must learn to speak some kind of Chinese and read and write Hanzi (Chinese characters) as well as the sound representation script of Hanyu Pinyin, through which students learn how to pronounce Chinese Hanzi (Finifrock \& Schilken, 2015). In most cases, both students' mother language and Chinese cannot develop well. In some rural primary schools, teachers and students share a minority language, teachers often try to help students learn the content of subjects and grasp school language by using minority language unsystematically in the classroom. Teachers view that the use of minority language is deleterious to the learning of the pronunciation of standard Chinese thus prevent them from performing satisfactorily in the comparative examinations in the area. As the proficiency of students' Chinese progress, less mother tongue supports are provided. In some small roadside towns, teachers use varieties of or no minority languages, students have to study through local dialects which they don't speak at home and rarely speak in their village. In recent times, an increasingly large members of fully qualified teachers from other ethnicities are employed and ported, thus teachers cannot even provide students little L1 supports, leaving students have to study in an unfamiliar language.

The types of trilingual education in Dong minority areas can be defined as the last two models, i.e. the Transitional and Depreciative models (Liu \& Shan, 2016). Chinese is predominantly the language of education. Students need to access to all facets of academia through Chinese. Not only the medium of instruction, but also the materials and methods of instruction are all designed to teach students whose mother tongue is Chinese. The minority students' mother tongue is merely used until sufficient Chinese have been input to students as to allow teachers stop using their L1 and make further progress in teaching. Without systematic L1 supports, minority students with a low or middle achievement range consequently develop as limited bilingual mono-literate students in L2 (Finifrock \& Schilken, 2015). Moreover, it is difficult to encourage the use of L1 in the classroom, for educational officials, teachers and students in the communities doubt that the use of L1 can truly be beneficial to students' educational performance, influenced by the notion that students' mother tongue will hinder the mastery of Chinese and thus the educational advancement.

When Chinese is valued as power, control and success in education (Zhou, 2001), students fails to acquire an effective knowledge of Chinese would lose the motivation for learning. Therefore, they either quit school or simply stay with tedious slowness through school life, waiting for the time when they complete school and going to work in factories in coastal areas. On the other hand, students with high motivation and can success in schooling would be prolonged absent from home. The lack of initiation of their own culture may result in some kind of estrangement and in 
the long term language loss (Finifrock \& Schilken, 2015). In both cases, the result is the reduction of the use of students' mother tongue, thus few students developed into balanced bilinguals, irrespective of their Chinese ability or consequential educational success.

The provision and quality of English teachers in Guizhou Dong minority education system differ at various levels of schools (Finifrock \& Schilken, 2015; Liu \& Shan, 2016). Primary schools are less staffed with less qualified teachers than junior school, which are staffed less qualified teachers than senior schools, because English become more important in the examinations at higher levels of the educational system. This correspondently indicates that there are more sufficient and qualified English teachers at higher levels of schools. Some primary schools in towns and villages lack or no professional English teachers. This situation will lead to negative impact on English education by exposing new English learners to teachers who have less English ability and inappropriate language use. Students in turn, would develop inferior English communication habits, poor pronunciation and literacy competence and lack the confidence of learning English. As they move to junior school, their teachers usually have more English language ability, find that it is difficult to correct the habitual errors developed by previous years of lower instruction. The situation is worse when they move to higher educational system, where teachers with most English language knowledge and communicative capabilities are concentrated. The teachers comment that most students are not prepared for high level English study.

The ethnicities of English teachers are mainly Miao and Dong ethnic minority in rural areas of Guizhou. But the percentage of Dong minority teachers and those who can speak Dong ethnic language is relatively low as a result the mixed inhabitant of Dong ethnic groups with the other ethnic groups. Similarly, students in the classroom are often of mixed ethnicities. Therefore, minority language is rarely used in English teaching.

\section{CONCLUSION}

To have a full understanding of multilingual education in China, it is necessary to expand the research scope in any specific minority area and from wider research perspective, such as from the fields of applied linguistic, sociolinguistic and multilingualism. To understand the shortages and problems existing in multilingual education in China, more deepen research are needed understand diverse elements of multilinguals' learning in terms of their cognition, social context and access of language resources. Based on it, curriculum is further developed to meet the needs of multicultural learners in the 21st century. It is argued that the study of the status quo of multilingual education can make a great contribution to the design of more relevant language policies, teaching practices, learning resources.

\section{REFERENCES}

[1] Adamson, B. \& Feng, A. W. (2009). A comparison of trilingual education policies for ethnic minorities in China. Compare: A Journal of Comparative and International Education, 39, 321-333.

[2] Adamson, B., \& Feng, A. W. (2014). Models for trilingual education in the People's Republic of China. In D. Gorter, V. Zenotz \& J. Cenoz (Eds.), Minority languages and multilingual education. Berlin: Springer, 29-44.

[3] Cenoz, J. (2003). The additive effect of bilingualism on third language acquisition: A review. International Journal of Bilingualism, 7(1), 71-87.

[4] Clyne, M., Hunt, C. R. \& Isaakidis, T. (2004). Learning a community language as a third language. International Journal of Multilingualism, $1(1,33-52$.

[5] Constitution of the People's Republic of China. (1982). http://english.peopledaily.com.cn/constitution/constitution.html. Accessed 16 June 2011.

[6] Denwood, P. (1999). Tibetan. Amsterdam: John Benjamins.

[7] Fei, X. T. (1989). Plurality within the organic unity of the Chinese nation. Journal of Beijing University, 4, 1-19.

[8] Feng, A. F. \& Adamson, B. (eds.). (2015). Trilingualism in Education in China: Models and Challenges. Dordrecht, The Netherlands: Springer.

[9] Finifrock, J. E. \& Schilken, D. (2015). Emerging trilingualism among the Dong minority in Guizhou Province. In A. W. Feng \& B. Adamson (Eds.), Trilingualism in education in China: Models and challenges. Dordrecht, the Netherlands: Springer, 199-221.

[10] Gu Y. S., \& Luo, S. J. (2003). The Study of Chinese Ethnography. Harbin: Heilongjiang People's Publishing House.

[11] Hu, D. Y. (2007). Trilingual education for members from ethnic minority nationalities in Yunnan. Kunming: Yunnan University Press.

[12] Jiang, Q. X., Liu, Q. G., Quan, X. H. \& Ma, C. Q. (2007). EFL education in ethnic minority areas in Northwest China: An investigation in Gansu Province. In A. Feng (Ed.), Bilingualism and bilingual education in China. Clevedon: Multilingual Matters, 240-257.

[13] Law of the People's Republic of China on Regional National Autonomy. http://www.china.org.cn/english/government/207138.htm. Accessed 16 June 2011.

[14] Law of the People's Republic of China on the Standard Spoken and Written Chinese Language (Order of the President No.37). (2000). http://www.gov.cn/english/laws/2005-09/19/content_64906.htm. Accessed 16 June 2011.

[15] Liu, C.Y. \& Shan, F. F. (2016). A Survey of the Status Quo of Trilingual Education in Dong Ethnic Area in Guizhou Province. Journal of Research on Education for Ethnic Minorities, 1, 61-69.

[16] Ministry of Education. (2001a). Guiding ideas to promote the English curriculum in primary schools by the Ministry of Education. No. 2 Document issued by the Ministry of Education (In Chinese).

[17] Ministry of Education. (2001b). Standard of English courses for 9-year compulsory education and general senior secondary schools (for experiment). Beijing: Beijing Normal University Press (In Chinese). 
[18] Ministry of Education. (2001c). Guidelines for improving the quality of undergraduate teaching. Beijing: Ministry of Education (In Chinese).

[19] Tsung, L. (2009). Minority languages, education and communities in China. New York: Palgrave Macmillan.

[20] Yang, J. (2005) English as a third language among China's ethnic minorities. International Journal of Bilingual Education and Bilingualism, 8(6), 552-567.

[21] Zeng, L. (2010). The Development of Metalinguistic Awareness of Hmong Learners in Third Language Acquisition. Unpublished PhD dissertation. Chongqing: Southwest University.

[22] Zhou, M. (2000). Language policy and illiteracy in ethnic minority communities in China. Journal of Multilingual and Multicultural Development, 21, 129-148.

Feifei Shan was born in Guizhou, China in 1984. She is currently a PHD candidate of Applied Linguistics in the College of International Studies, Southwest University, Chongqing, China.

Her research interests are English language teaching, multilingualism, multilingual education, and systemic functional lingui stics. Her current research is a fieldwork-based multilingual educational intervention project in Guizhou Minority areas, China. She focuses on Dong and Hmong ethnic minority groups in particular. She publishes in the field of multilingualism and English teaching, with a particular focus on Dong and Hmong students learning English.

She is the assistant of the chairman of China Association of Multilingualism and Multilingual Education. 